\title{
Van Der Waals Heterostructures between Small Organic Molecules and Layered Substrates
}

\author{
Han Huang ${ }^{1,2, *}$, Yingbao Huang ${ }^{1}$, Shitan Wang ${ }^{1}$, Menglong Zhu ${ }^{1}$, Haipeng Xie ${ }^{1}$, Lei Zhang ${ }^{3}$, \\ Xiaoming Zheng ${ }^{1}$, Qiliang Xie ${ }^{1}$, Dongmei Niu ${ }^{1}$ and Yongli Gao ${ }^{1,2,4, *}$ \\ 1 Hunan Key Laboratory of Super-microstructure and Ultrafast Process, School of Physics and Electronics, \\ Central South University, Changsha 410083, China; 142211010@csu.edu.cn (Y.H.); shitan@csu.edu.cn (S.W.); \\ menglong6914@csu.edu.cn (M.Z.); xiehaipeng89@163.com (H.X.); 15874954147@163.com (X.Z.); \\ xqldeworld@csu.edu.cn (Q.X); mayee@csu.edu.cn (D.N.) \\ 2 State Key Laboratory of Powder Metallurgy, Central South University, Changsha 410083, China \\ 3 Department of Physics, National University of Singapore, 2 Science Drive 3, Singapore 117542, Singapore; \\ e0001007@u.nus.edu \\ 4 Department of Physics and Astronomy, University of Rochester, Rochester, NY 14627, USA \\ * Correspondences: physhh@csu.edu.cn (H.H.); ygao@csu.edu.cn (Y.G.); \\ Tel.: +86-731-8883-0323 (H.H.); +86-731-8883-0486 (Y.G.)
}

Academic Editors: Cristina E. Giusca and Spyros Yannopoulos

Received: 16 July 2016; Accepted: 30 August 2016; Published: 9 September 2016

\begin{abstract}
Two dimensional atomic crystals, like grapheme $(\mathrm{G})$ and molybdenum disulfide $\left(\mathrm{MoS}_{2}\right)$, exhibit great interest in electronic and optoelectronic applications. The excellent physical properties, such as transparency, semiconductivity, and flexibility, make them compatible with current organic electronics. Here, we review recent progress in the understanding of the interfaces of van der Waals $(\mathrm{vdW})$ heterostructures between small organic molecules (pentacene, copper phthalocyanine (CuPc), perylene-3,4,9,10-tetracarboxylic dianhydride (PTCDA), and dioctylbenzothienobenzothiophene $\left(\mathrm{C}_{8}\right.$-BTBT) $)$ and layered substrates $\left(\mathrm{G}, \mathrm{MoS}_{2}\right.$ and hexagonal boron nitride $\left.(h-\mathrm{BN})\right)$. The influences of the underlying layered substrates on the molecular arrangement, electronic and vibrational properties will be addressed.
\end{abstract}

Keywords: interface; self-assembly; growth behavior; vdW heterostructures; 2D organics; SPM; OFET; capping layer

\section{Introduction}

Organic (opto-)electronics are attracting tremendous attention for their mechanical flexibility, light weight, low cost, and available large scale production in organic light emitting diodes (OLEDs), organic photovoltaics (OPVs), and organic field effect transistors (OFETs) [1-5]. The quality of organic semiconductor thin films is one of the key components for a better device performance. Figure 1a-d shows the molecular structures of four air-stable candidates for organic electronics, pentacene, copper phthalocyanine $(\mathrm{CuPc})$, perylene-3,4,9,10-tetracarboxylic dianhydride (PTCDA) and dioctylbenzothienobenzothiophene $\left(\mathrm{C}_{8}\right.$-BTBT), respectively. The anisotropic structures suggest orientation-dependent electronic properties. For example, pentacene possesses a relatively higher mobility in its b-c plane than a-b plane, as shown in Figure 1e [6,7]. Thus, various substrates, metals [8-10], native oxide silica [11-14], and layered materials [6,7,15-18], have been chosen for the growth of high quality thin films. In order to optimize the devices performance, it is essential to clarify how the interactions between molecules and substrates affect the growth of organic thin films.

The two dimensional (2D) derivatives of layered materials, such as single- or few-layered (SL, FL) molybdenum disulfide $\left(\mathrm{MoS}_{2}\right)$, hexagonal boron nitride $(h-\mathrm{BN})$, and graphene $(\mathrm{G})$, whose structures are schematically shown in Figure $1 \mathrm{f}$ and exhibiting an atomically flat surfaces without 
dangling bonds, are thought to be perfect candidates to fundamental researches and practical applications. G has the advantages such as very high charge carrier mobility, good flexibility, and transparency to be used as a transparent electrode substituting indium-tin oxide (ITO) $[19,20]$. $h$-BN is an insulating isomorph of $\mathrm{G}$ with covalent bonding boron and nitrogen atoms occupying the inequivalent positions, possessing a low dielectric constant. $\mathrm{MoS}_{2}$ is composed by one layer of Mo atoms stacked between two sulfide layers and used as channel materials in FETs because of its high on/off ratio, low sub-threshold swing value, and good carrier mobility [21-24]. G, $\mathrm{MoS}_{2}$, and $h$-BN are all chemically inert, avoiding bonding strongly when integrating with different dimensional crystals at the interface and leading to 2D-2D and 0D-2D (organic molecules-2D) van der Waals (vdW) heterostructures [25-27]. For example, $\mathrm{MoS}_{2}-\mathrm{G}$ vdW heterostructure shows that close to the Fermi level, no significant charge transfer doping is detected from $\mathrm{MoS}_{2}$ to G [28,29]. Besides, organic molecules are able to grow into well-ordered thin film with a high degree of crystallinity on 2D substrates and form vdW heterostructures. Such vdW heterostructures possess potential applications in FET devices [30]. Moreover, the excellent physical properties, such as transparency and flexibility, make them compatible with current organic (opto-)electronics.

This review consists of following six sections: I tuning the orientation of pentacene, II pentacene on layered substrates, III CuPc on layered substrates, IV $C_{8}$-BTBT on layered substrates, V PTCDA on layered substrates, and VI conclusions.

(a)

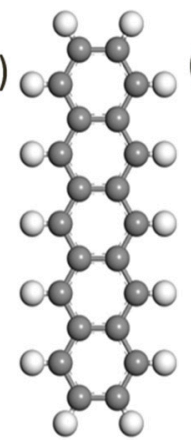

(b)

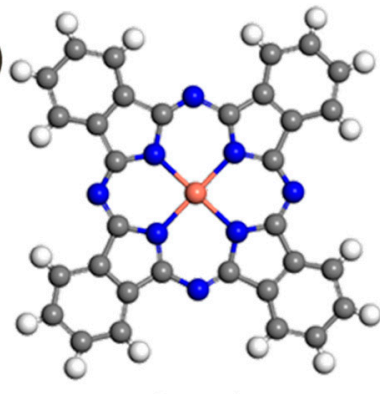

(c)

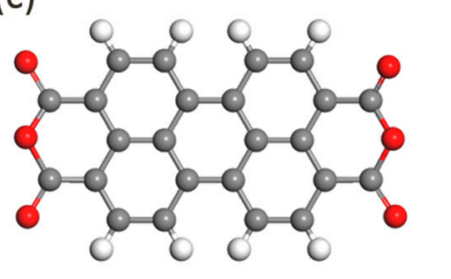

$\mathrm{H}$

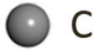

○

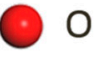

$\mathrm{S}$

$B$

(d)

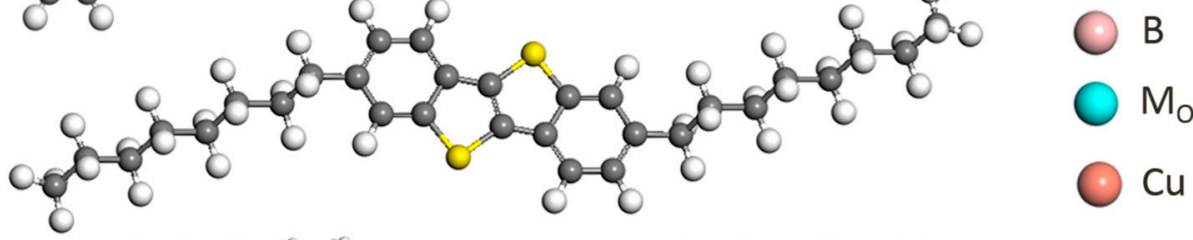

(e)
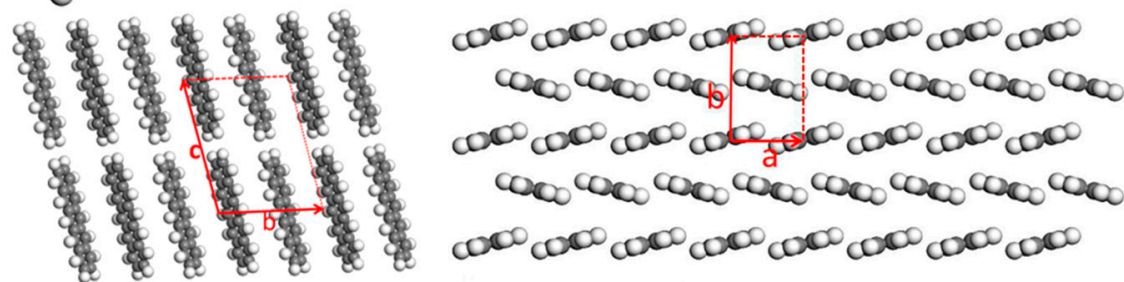

(f)

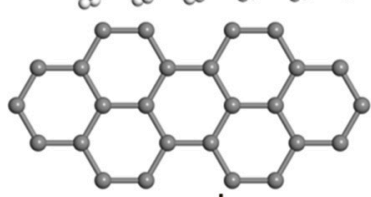

graphene

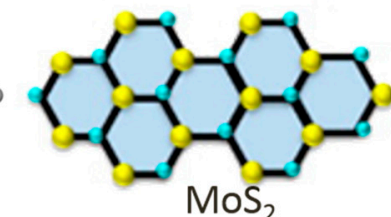

$\mathrm{MoS}_{2}$
100000000000000001000000000000000
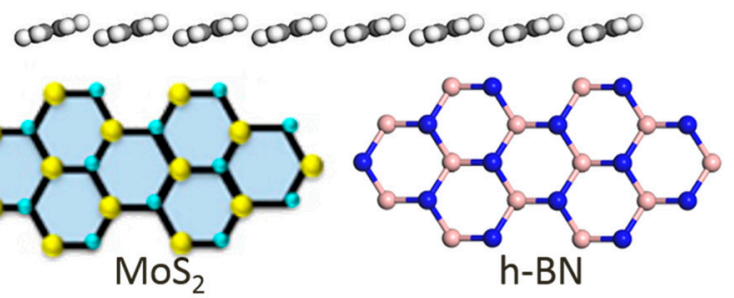

Figure 1. Molecular structures of pentacene (a), CuPc (b), PTCDA (c), $\mathrm{C}_{8}-\mathrm{BTBT}(\mathbf{d})$, respectively. (e) The $\mathrm{a}-\mathrm{b}$ and $\mathrm{b}-\mathrm{c}$ planes of a pentacene single crystal, showing the anisotropy of small organic molecules. (f) Schematics of three layered substrates, G, $\mathrm{MoS}_{2}$ and $h$-BN. 


\section{Tuning the Orientation of Pentacene}

As a well-known gate dielectric, $\mathrm{SiO}_{2}$ is one of most usual substrates to study the properties of thin films of small organic molecules, for example, pentacene. The AFM image in Figure 2a shows the typical morphological features of $\sim 3 \mathrm{ML}$ (ML, monolayer, a full layer of molecules in the standing-up configuration) pentacene thin films on $\mathrm{SiO}_{2}$ [12]. Such films are composed by dendritic grains with flat surfaces and well-ordered crystalline structures in size of few micrometers, indicating a kinetics-limited Volmer-Weber growth mode [31,32]. The corresponding inset shows the nucleation and extension of pentacene in the first monolayer into dendritic grains, indicating presence of plenty of grain boundaries in thicker films. The average step height of $\sim 1.5 \mathrm{~nm}$, close to the length of one pentacene molecule, suggests that pentacene molecules always stand up on $\mathrm{SiO}_{2}$ (molecular $\mathrm{a}-\mathrm{b}$ plane parallel to the substrate surface) as shown in Figure $2 \mathrm{~d}$, which can be attributed to the relatively weak interfacial interaction between pentacene and $\mathrm{SiO}_{2}$. Consequently, the charge carriers in such pentacene thin films prefer to lateral transport along the overlapped $\pi$ orbitals with high mobilities up to $5 \mathrm{~cm}^{2} / \mathrm{Vs}$ [33]. However, the existed plenty of grain boundaries may scatter the charge carriers and reduce the mobilities. Given that molecule-substrate and molecule-molecule interactions predominantly determine the film structures, so as to enhance the device's performance, an adequate substrate is urgently required to ensure higher-crystalline pentacene thin films.

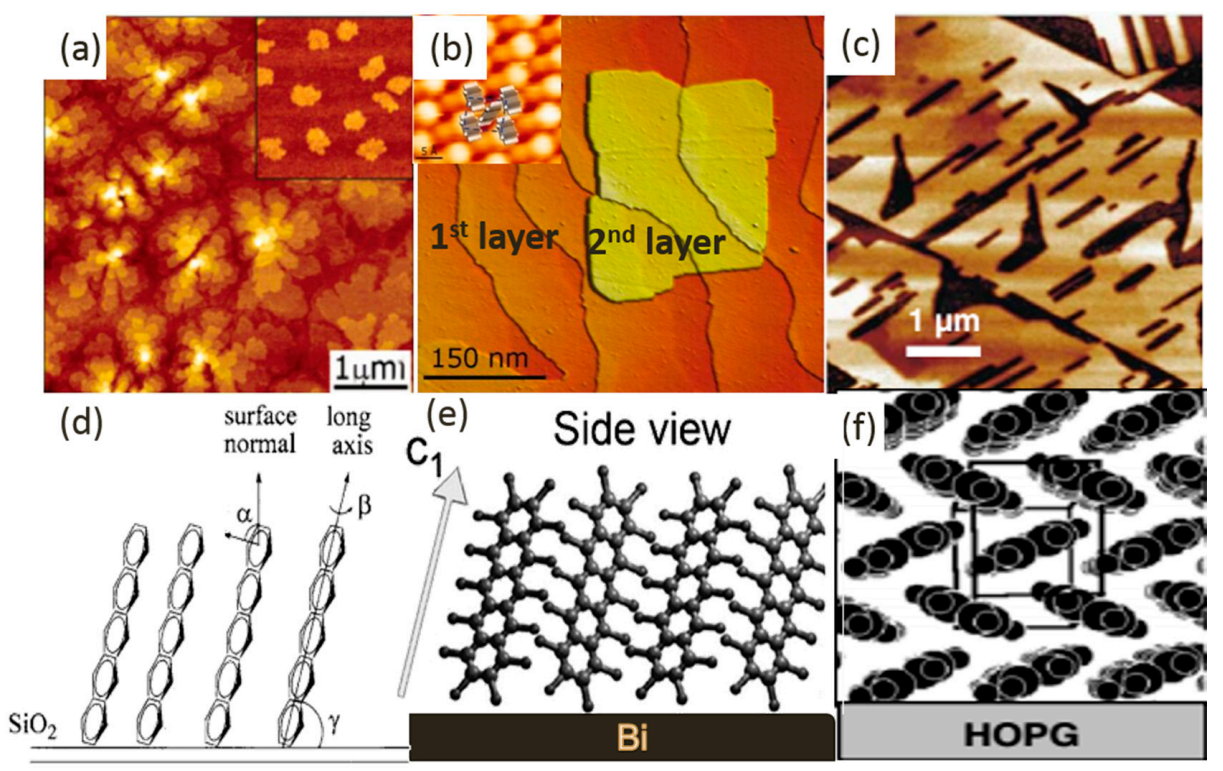

Figure 2. Morphologies of pentacene thin films on different substrates. (a) AFM topography image of fractal islands of pentacene on $\mathrm{SiO}_{2}$ at a coverage of $\sim 3 \mathrm{ML}$. Inset: nucleation at submonolayer coverage. (b) STM image of pentacene on Bi(001) at a coverage of slightly over $1 \mathrm{ML}$. Inset: high-resolution STM image showing pentacene molecules in the first layer in a standing-up configuration. (c) Twelve nanometer thick pentacene film on Highly Oriented Pyrolytic Graphite (HOPG). (d-f) Schematic representations of the proposed molecular packing corresponding to image in panel $(\mathbf{a}-\mathbf{c})$. Panel a reprinted with permission from [12]. Copyright 2004 American Chemical Society. Panel $b$ reprinted from [8] with the permission of AIP Publishing. Panels c, f reprinted with permission from [6] as follows: Koch, N. Physical review letters, 96 (15), 156803, 2006. Copyright 2006, American Physical Society.

STM image in Figure $2 \mathrm{~b}$ shows that $\mathrm{Bi}(001)$ is covered by an ordered single layer pentacene entirely and a second layer partially (with brighter contrast) [8]. The pentacene layer grows in a step flow mode, like $h$-BN grown on $\mathrm{Ru}(0001)$ [34], which can effectively reduce the grain boundaries and result the first layer pentacene in grains with a larger size exceeding $200 \mu \mathrm{m}$ in diameter. The inserted molecularly-resolved STM image shows aligned spots. Each of them corresponds to 
a single standing-up pentacene molecule, indicating the pentacene molecular $a-b$ plane parallel to $\mathrm{Bi}(001)$, as show in Figure 2e. Angle Resolved Photoemission Spectroscopy (ARPES) measurements demonstrate a higher highest occupied molecular orbital (HOMO) dispersion and more delocalized charge carriers than theoretical calculations along three high symmetrical directions $(\bar{\Gamma}-\bar{M}, \bar{\Gamma}-\bar{Y}$ and $\bar{\Gamma}-\bar{X}$ ), which means a larger overlap of $\pi$-orbitals and higher carrier mobilties [9]. The results indicate the $\mathrm{Bi}(001)$ indeed improved the crystallinity of pentacene films and induced higher mobility.

HOPG is a famous inert substrate for surface science researches. The AFM image in Figure 2c shows the morphology of $\sim 12 \mathrm{~nm}$ thick pentacene films on HOPG, which is characterized by large block-like ordered crystals with deep trenches [6]. On the contrary to above two cases, the long axes of pentacene molecules are parallel to the substrate surface according to $\mathrm{X}$-ray diffraction results. Such a lying-down arrangement, as schematically shown in Figure $2 \mathrm{f}$, can be attributed to the improved interfacial $\pi-\pi$ interactions due to the epitaxial growth of pentacene on HOPG. The rather weak adsorption energy of the molecules on graphite enables a slight tilting of the molecules at the interface and thus allows the formation of crystalline multilayer films by suppressing any strain due to lattice mismatch between the molecular film and the substrate [35]. The films are possibly in orthorhombic polymorph and possess fiber textures with (100) as the fiber long axis along the surface normal. Thus, they have high enough crystallinity to show a HOMO-derived band dispersion of $\sim 190 \mathrm{meV}$ at room temperature, which is absent for pentacene grown on $\mathrm{SiO}_{2}$ [6]. The results indicate that layered substrates like HOPG and $\mathrm{MoS}_{2}$, moreover, their single- or few- layered derivatives like G and $\mathrm{MoS}_{2}$, may improve the crystallinity of thin films of small organic molecules.

\section{Pentacene on Layered Substrates}

In terms of devices, $\mathrm{G}$ is an ideal electrode material due to its outstanding conductivity, flexibility, and transparency. Conductive and transparent monolayer $\mathrm{G}$ can be used as a template to tune pentacene molecular orientation from standing-up to lying-down in well-defined films $[15,36]$. The AFM image in Figure 3a shows that the morphology of $50 \mathrm{~nm}$ thick pentacene films on CVD-G-covered and bare $\mathrm{SiO}_{2}$ has an abrupt change cross the boundary, which revealed remarkable differences in growth and the modulation effect of substrates. Pentacene films on G (left-hand side) show a highly ordered block-like crystals with deep trenches texture, similar to on HOPG, while on $\mathrm{SiO}_{2}$ (right-hand side) are in typical polycrystalline grains [15]. They differ greatly in crystallinity, grain size, and orientation. Both the angle-dependent near-edge X-ray absorption fine structure (NEXAFS) and two-dimensional grazing incidence X-Ray diffraction (2D GIXRD) measurements corroborate that pentacene molecules in the first layer are in a lying-down orientation, while slightly tilted relative to the G plane in subsequent layers, as depicted in Figure 3d. It is ascribed to that the interfacial $\pi-\pi$ interaction is reduced when pentacene grows into several layers [15]. It is well adapted to the cases of pentacene on G-covered glass [36] and perfluoropentacene on G-covered quartz [37]. It's also important to mention that polymer residues remaining on $G$ surfaces induce a stand-up orientation of pentacene [15]. The Fe film morphology was influenced by substrate surface defects [38]. Considering this reason, there can be a distinct structure and orientation of pentacene film if the substrate surface exhibits defects or becomes rough, because the template effect is no longer operative. In that case, molecules adsorb in an upright orientation and continue to grow as (001) oriented films. Thus, it is a crucial factor which avoids surface defects and roughness when utilizing template-guided molecular film growth [35]. The particular interaction between $\mathrm{G}$ and small molecules [39] is used to govern both the thin film morphology and electronic characteristics of pentacene films.

The AFM image in Figure 3b displays the morphology of $40 \mathrm{~nm}$ thick pentacene on $\mathrm{SiO}_{2}$ covered with/without mechanically exfoliated $2 \mathrm{~L} \mathrm{MoS}_{2}$ (blue/red dash block) [40]. On the $\mathrm{MoS}_{2}$ side, pentacene, perhaps in a lying-down configuration (Figure 3e), is more compact and homogeneous but in smaller grains. The abrupt change in the pentacene film grain size coincides with the boundary with the underlying $\mathrm{MoS}_{2}$. 
The AFM image in Figure 3c shows the well-defined crystal facets of $\sim 2$ ML pentacene grown on mechanically-exfoliated $h$-BN [7], indicating that pentacene is highly-crystalline and grows in a layer-by-layer mode with obvious difference in the first three layers. The average thickness of the wetting layer $(\mathrm{WL})$, the first $(1 \mathrm{~L})$, and the second conducting layer $(2 \mathrm{~L})$ are $0.5,1.14$, and $1.58 \mathrm{~nm}$, respectively. The subsequent layers have the same height and molecular packing as $2 \mathrm{~L}$. The thickness of WL approximates the length of pentacene molecule along b-axis $(0.606 \mathrm{~nm})$, and far less than that along c-axis $(1.601 \mathrm{~nm})$ [12], which indicates the molecules adopt the lying-down configuration. In addition, the thickness of $2 \mathrm{~L}$ is consistent with the (001) plane spacing of thin film phase $(1.45 \mathrm{~nm})$. However, $1 \mathrm{~L}$ is clearly in a new polymorph which slightly differs with $2 \mathrm{~L}$. The transitional height implies more tilted molecular packing compared to $2 \mathrm{~L}$, as schematically illustrated in Figure $3 \mathrm{f}$. The molecular packing is very different with on $\mathrm{G}$ and $\mathrm{MoS}_{2}$.
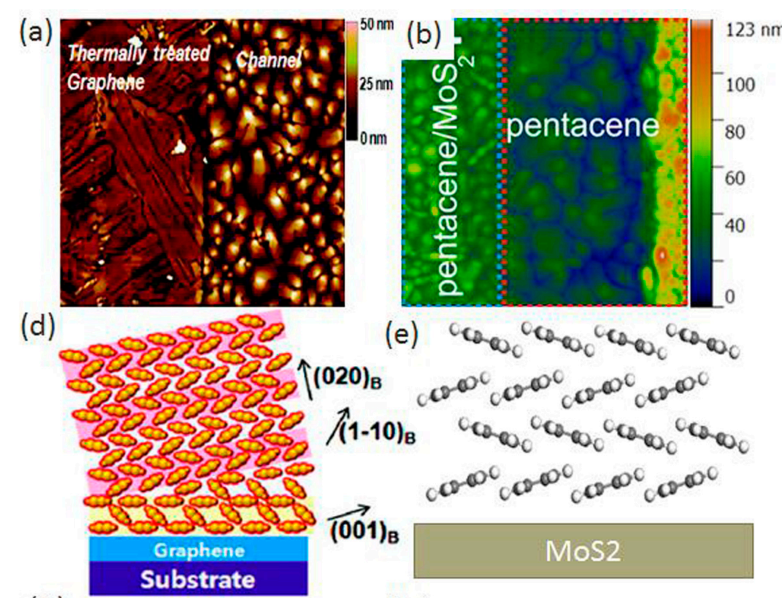

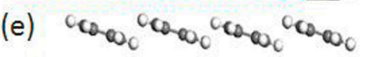
${ }_{0} 0000{ }_{0} 00000000000000$

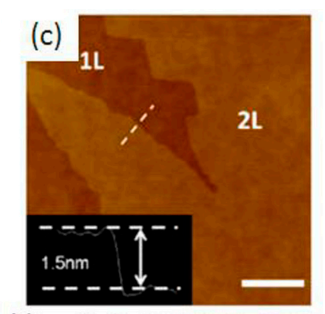

(f)
$2 \mathrm{~L}$

2L
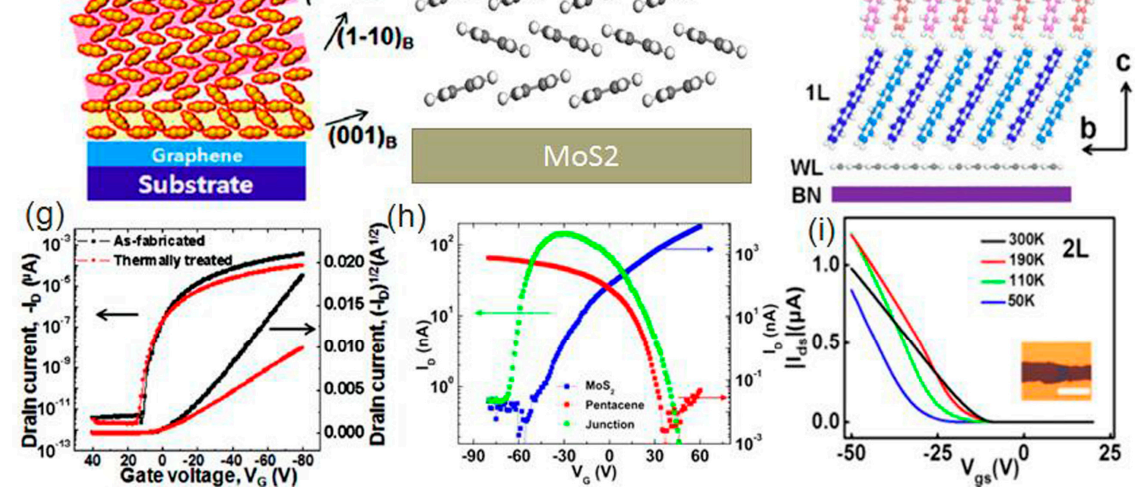

WL
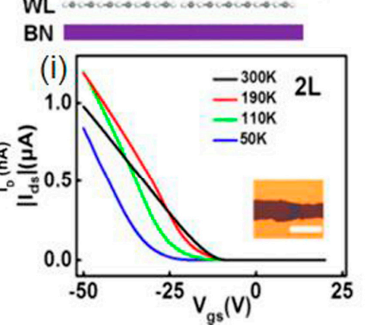

Figure 3. Epitaxial growth of pentacene molecular crystals on layered substrates. (a) AFM image of $\sim 50 \mathrm{~nm}$ thick pentacene films over the sharp linear boundary between G-covered and bare $\mathrm{SiO}_{2}$. (b) Forty nanometer pentacene films over the boundary between $\mathrm{MoS}_{2}$-covered and bare $\mathrm{SiO}_{2}$. (c) Approximately two ML pentacene crystals with a flat-lying wetting layer on mechanically exfoliated $h$-BN. (d-f) Schematic illustrations of the molecular packing of $(\mathbf{a}-\mathbf{c})$, respectively. $(\mathbf{g}-\mathbf{i})$ The transfer characteristics of FETs based on the films in $(\mathbf{a}-\mathbf{c})$, respectively. Panel a,d,g reprinted with permission from [15]. Copyright 2011 American Chemical Society. Panel b, h reprinted with permission from [40]. Copyright 2015 American Chemical Society. Panel c, f, i reprinted with permission from [7] as follows: Zhang, Y. Physical review letters, 116 (1), 016602, 2016. Copyright 2016 American Physical Society.

Figure $3 g-i$ shows the transfer characteristics of pentacene based OFETs with $\mathrm{G}, \mathrm{MoS}_{2}$ and $h$-BN as function layers, respectively. Figure $3 g$ demonstrates transfer characteristics of lateral FETs using monolayer $\mathrm{G}$ with/without PMMA residues (black/red curve) as electrodes. The devices with/without PMMA residues show an average field-effect mobility of $1.2 / 0.4 \mathrm{~cm}^{2} / \mathrm{Vs}$ and a comparable current on-off ratio of $10^{8}$. The poorer field-effect mobility is due to the orientation of the pentacene long axis parallel to the substrate plane on clean $\mathrm{G}$. That is, the $\pi$ conjugate direction is normal to electron transport direction of planar FET devices.

Figure $3 \mathrm{~h}$ displays the transfer characteristics of a $\mathrm{MoS}_{2}$ FET (blue), a pentacene FET (red), and a type II p-n heterojunction based on pentacene $/ \mathrm{MoS}_{2}$ (green), respectively [40]. The gate-tunable 
asymmetric antiambipolar transfer characteristic of pentacene/ $\mathrm{MoS}_{2}$ heterojuntion is different than the symmetric one with a $\mathrm{MoS}_{2}-\mathrm{WSe}_{2}$ p-n heterojunctions [41,42], suggesting harnessing to achieve simultaneous phase [43] and amplitude [44] shift-keying for wireless telecommunication technologies. In addition, this heterojunction exhibits a photovoltaic effect but poor power conversion efficiencies of $\sim 0.004 \% @ 625 \mathrm{~nm}$, Performance of FET devices is unsatisfied because of a low on/off ratio and mobility. It seems that the reduced carrier diffusion length results from charge carrier scattering and trapping due to smaller grain size. Hence, the crystalline of pentacene on MoS2 continue to be a primary issue for application.

Figure $3 \mathrm{i}$ shows the temperature dependent transfer characteristics of a $2 \mathrm{~L}$ pentacene $/ h$-BN based FET [7]. The extracted field effect mobility is about 3 and $5.2 \mathrm{~cm}^{2} / \mathrm{Vs}$ at room- and low-temperature $(110 \mathrm{~K})$, respectively, far surpassing devices based on pentacene polycrystalline thin films at similar temperatures. On the contrary to the bandlike transport of $2 \mathrm{~L}$ devices, the $\mathrm{WL}$ devices exhibit no conduction due to the absence of intralayer $\pi-\pi$ stacking, and the $1 \mathrm{~L}$ devices display characteristic of 2D hopping transport mode. In $2 \mathrm{~L}$, a sufficient extended density of states along a-b plane caused by the $\pi$ orbital laterally-overlapping leads to bandlike transport for planar FETs. In 1L, a more tilted molecular orientation results in disconnected bonding and localization in both directions. The strong modulation demonstrates that $h$ - $\mathrm{BN}$ is an excellent candidate for an insert layer which enables the conversion of molecules' arrangement by vdW interactions.

\section{CuPc on Layered Substrates}

The modulation of layered substrates on the growth of $\mathrm{CuPc}$ are also interesting. Figure $4 \mathrm{a}, \mathrm{b}$ show the AFM topography images CuPc on glass covered with/without CVD-grown G [45]. On bare glass, elongated CuPc grains, $94 \pm 34 \mathrm{~nm}$ long and $35 \pm 6 \mathrm{~nm}$ wide, are observed with a root mean squared film roughness of $2.0 \mathrm{~nm}$, and similar to previous AFM observations of standing up oriented $\mathrm{CuPc}[46,47]$.Round CuPc grains are observed on a few layers of G (FLG) with a greater roughness of $4.2 \mathrm{~nm}$. The 2D-GIXRD pattern in Figure $4 \mathrm{~d}$ for $\mathrm{CuPc}$ on bare glass only shows one single sharp peak concentrated on the meridian $\left(\mathrm{q}_{\mathrm{xy}}=0\right)$, implying that $\mathrm{CuPc}$ molecules are oriented perpendicularly to the surface of the glass substrate, similarly on Si [48]. On the contrary, the pattern in Figure 4e shows multiple new diffraction points for CuPc on FLG-covered glass. Furthermore, it is not dispersed much, indicating that $\mathrm{CuPc}$ molecules are well oriented on G-covered glass [49]. Thus, CuPc adopts a near face-on orientation with the molecular plane tilted on average $9^{\circ}$ with respect to the substrate. The continued appearance of the (100) reflection along the meridian indicates that there are still some crystallites adopt the edge-on configuration in the film [48]. Conductive atomic force microscopy (C-AFM) measurements show that at a single-grain level CuPc on (G covered) PEDOT:PSS/ITO presents a hole mobility of $(1.9 \pm 0.2) \times 10^{-3}\left((1.6 \pm 0.2) \times 10^{-2}\right) \mathrm{cm}^{2} /$ Vs. G-templated CuPc thin films exhibit an order of magnitude higher out-of plane hole mobility relative to untemplated thin films. Whether the $\mathrm{G}$ coating affects the charge injection requires further research.

The AFM image in Figure 4c presents the 1D nanorod-like structure of $4.8 \mathrm{~nm}$ thick CuPc on bulk $\mathrm{MoS}_{2}(0001)$ [50]. The corresponding 2D-GIXRD pattern in Figure 4f proves a good crystallization, as well as a standing-up orientation. It should be noted that this study was carried out in ambient conditions. In situ LEED patterns illustrate that $\mathrm{CuPc}$ molecules assemble into large domains at a thickness of $4.8 \mathrm{~nm}$ with the molecular plane (quasi-)parallel to the $\mathrm{MoS}_{2}(0001)$ substrate [51]. Thus, $\mathrm{MoS}_{2}$ may have different effect on CuPc growth compared with G. Furthermore, photodetectors based on the vdW heterostructure of $2 \mathrm{~nm}$-thick p-type CuPc/5L n-type $\mathrm{MoS}_{2}$ presents the highest performance with a photoresponsivity of $\sim 1.98 \mathrm{~A} / \mathrm{W}$, a detectivity of $\sim 6.11 \times 10^{10}$ Jones, and an external quantum efficiency of $\sim 12.57 \%$, due to the transfer of photo-generated charge carrier form CuPc to $\mathrm{MoS}_{2}$ and the $\mathrm{CuPc}$ layer thickness-dependent interlayer recombination processes across the $\mathrm{CuPc} / \mathrm{MoS}_{2}$ interface [52]. 
(a)
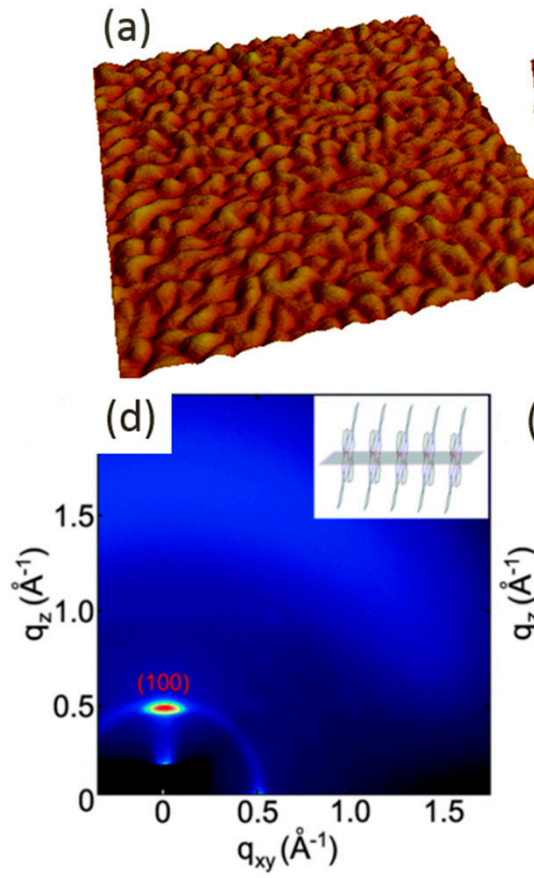
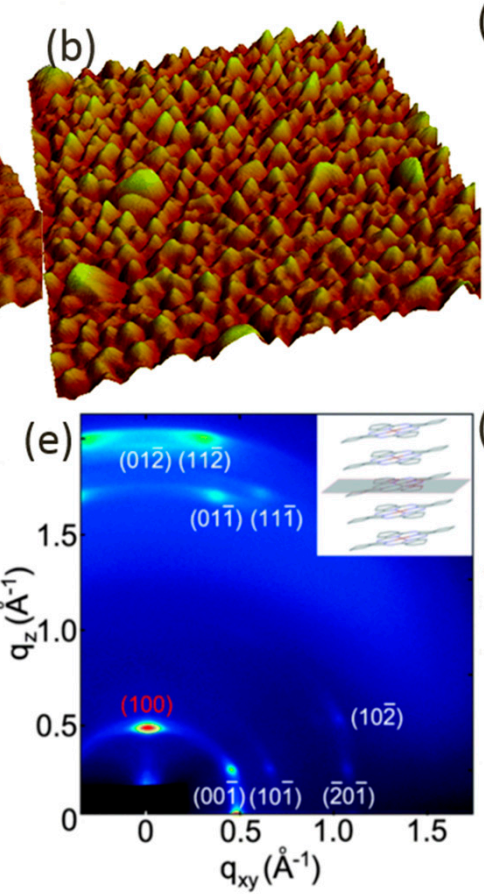

(c)

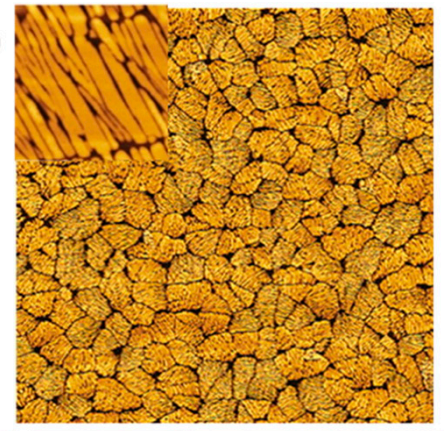

(f) 20

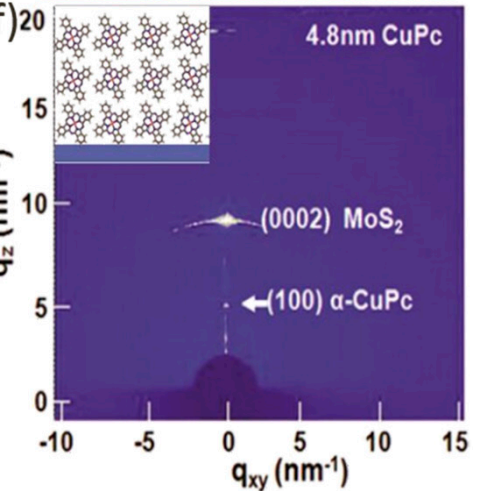

Figure 4. The AFM morphologic images and 2D-GIXRD images of CuPc on glass (a,d), G-covered glass $(\mathbf{b}, \mathbf{e})$, and bulk $\mathrm{MoS}_{2}(\mathbf{c}, \mathbf{f})$, respectively. The insets show the corresponding CuPc packing. Panel a, b, d, e is reproduced from [45] with permission from The Royal Society of Chemistry. Panel c, $\mathrm{f}$ is reprinted with permission from [50], copyright 2015 American Chemical Society.

Raman spectroscopy is an effective and non-destructive method at ambient conditions to determine surface characterization. Figure 5a demonstrates the spatially-averaged Raman spectra for a $50 \mathrm{~nm}$ thick pentacene film on glass covered with/without a monolayer of G [36]. The band at $1596(1533) \mathrm{cm}^{-1}$ can be assigned to a $B_{3 g}\left(A_{g}\right)$ mode. The intensity ratio between them $\left(R=I_{1596} / I_{1533}\right)$ can be used to quantitatively define the orientation of the pentacene long axis on different substrates [53]. For pentacene on $G$ (center), $R=5.6$, while on glass (upper) $R=0.22$. Thus, the pentacene molecules are lying almost flat on the $G$ surface, consistent with precious results [15,54].

Figure $5 \mathrm{~b}$ shows the Raman enhancement effect of $2 \mathrm{D}$ layered materials, such as $\mathrm{G}, h$-BN, and $\mathrm{MoS}_{2}$ on $\mathrm{CuPc}$ [55]. Compared to the low intensity of Raman signals for $\mathrm{CuPc}$ on blank $\mathrm{SiO}_{2} / \mathrm{Si}$ substrate, shown by the black curve in Figure $5 b, 1531,1450$ and $1340 \mathrm{~cm}^{-1}$ vibrational modes can be explicitly observed for $\mathrm{CuPc}$ on $\mathrm{G}, h$-BN, and $\mathrm{MoS}_{2}$ substrates. The enhancement factors of $\mathrm{CuPc}$ on $\mathrm{G}$ (blue line) and $h$-BN (red line) are stronger than on $\mathrm{MoS}_{2}$ (green line). Insulated $h$-BN with a strong B-N bond is favorable to strong dipole-dipole coupling and $\mathrm{G}$ with a nonpolar $\mathrm{C}-\mathrm{C}$ bond is a benefit to the occurrence of charge transfer. Thus, a remarkable Raman scattering enhancement requires strong molecule-substrate coupling and, thus, effective charge transfer between them. 

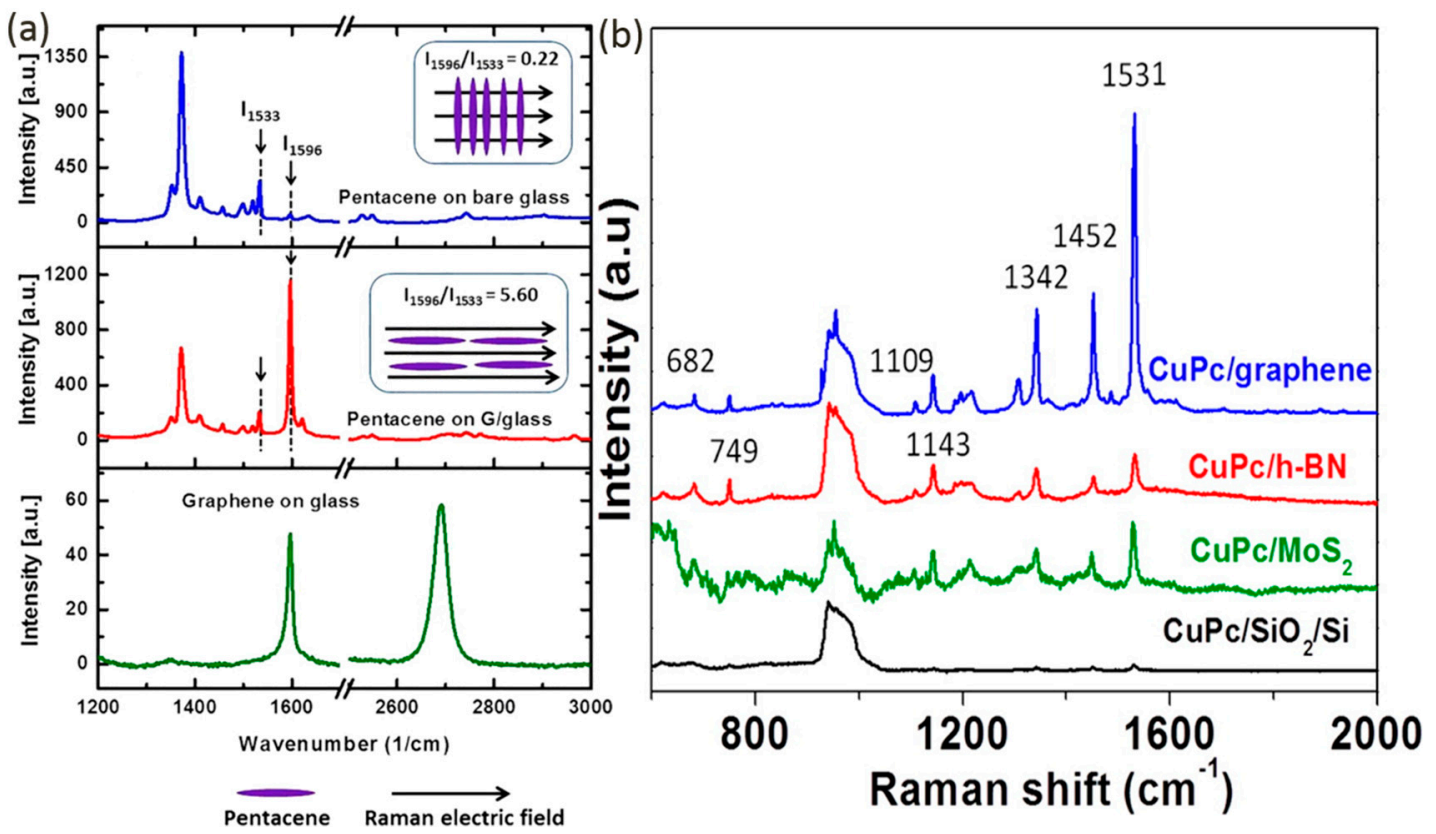

Figure 5. (a) Raman spectra from pentacene on glass without/with monolayer $G$, and from $G$ on glass. $(\lambda=532 \mathrm{~nm} ; 3.0 \mathrm{~mW})$. (b) Raman spectra from $2 \AA$ thick CuPc on G (blue line), on $h$-BN (red line), on $\mathrm{MoS}_{2}$ (green line), and on the blank $\mathrm{SiO}_{2} / \mathrm{Si}$ substrate (black line). Panel a reprinted with permission from [36], copyright 2015 American Chemical Society. Panel b reprinted with permission from [55], copyright 2015 American Chemical Society.

\section{C8-BTBT on Layered Substrates}

$\mathrm{C}_{8}$-BTBT can epitaxially grow on exfoliated $\mathrm{G}$ and $\mathrm{MoS}_{2}$ with precisely controlled thickness down to a monolayer into 2D molecular crystals for OFETs [56,57]. The AFM image in Figure 6a shows that $\mathrm{C}_{8}$-BTBT molecules prefer to grow on $\mathrm{G}$ than on $\mathrm{SiO}_{2}$ accompanied with a layer-by-layer manner and atomic smoothness due to the high diffusion coefficient. According to the measured thickness of the first two layers of 0.6 and $1.7 \mathrm{~nm}$, a schematic illustration of the $\mathrm{C}_{8}$-BTBT molecular packing is shown in the inset in Figure 6d, similar to above-mentioned case of pentacene on $h$-BN. Figure $6 \mathrm{~b}$ displays the AFM image of three layers $\mathrm{C}_{8}$-BTBT grown on $\mathrm{MoS}_{2}$ [57]. Interestingly, the average thickness of the first $\mathrm{C}_{8}$-BTBT layer on $\mathrm{MoS}_{2}$ is $\sim 1.4 \mathrm{~nm}$, suggesting no WL and the different effect of $\mathrm{MoS}_{2}$ on organic molecule growth to G. This is attributed to reduced interfacial interactions between $\mathrm{C}_{8}$-BTBT layer and $\mathrm{MoS}_{2}$ due to that $\mathrm{MoS}_{2}[58,59]$ is natively not a $\pi$-conjugated system and the lattice constants are rather different from $\mathrm{G}$. A higher density of nucleation sites on $\mathrm{MoS}_{2}$, especially at the edges, is attributed to the high density of sulfur vacancies in the mechanically-exfoliated monolayer $\mathrm{MoS}_{2}[60,61]$. The frequent and purposeful interruption and ambient exposure for AFM characterization does not distinctly affect the film growth, implying that the crystals are of pristine quality and stable in the ambient environment. Figure $6 \mathrm{c}$ shows the transfer characteristic of a $1 \mathrm{~L}$ $\mathrm{C}_{8}$-BTBT/ $h$-BN-based planar OFET at room temperature [56]. The calculated field-effect mobility reaches up to $10 \mathrm{~cm}^{2} / \mathrm{Vs}$, much higher than previously reported values for monolayer OFETs [62-66]. The most significant part of these results is that growing $\mathrm{C}_{8}$-BTBT molecule on layered substrates does not drastically alert the charge transport characteristic, signifying organic semiconductor crystal can be regarded as quasi-freestanding with minimal disturbance from the substrate.

Figure $6 \mathrm{~d}$ shows the calculated binding energy (BE) of a single $\mathrm{C}_{8}$-BTBT with different substrates, which depends highly on the underlying substrate. Such a BE gradient creates temperature windows for $\mathrm{C}_{8}$-BTBT thermodynamically stable on the corresponding substrates, resulting in self-limited organic molecule beam epitaxy (SLOMBE) [67]. Thus, highly precise, controllable, self-limited epitaxy of layered monocrystalline organic semiconductors $\left(\mathrm{C}_{8}\right.$-BTBT) and related heterojunctions 
( $\mathrm{C}_{8}$-BTBT/PTCDA) can be obtained on exfoliated $\mathrm{G}$ by controlling the substrate temperature. Figure 6e shows the AFM topography image of a heterojunction of bilayer (WL+1L) $\mathrm{C}_{8}$-BTBT/1L PTCDA/G, indicating the $\mathrm{C}_{8}$-BTBT was uniformly grown on PTCDA in a self-limited manner. The photodetector based on such a p-n junction displays a photoresponsivity of $\sim 0.37 \mathrm{~mA} / \mathrm{W} @ 514 \mathrm{~nm}$ laser, where the organic films are $\sim 15 \mathrm{~nm}$ thick to minimize the direct tunneling effects. Thus, by harnessing the vdW interactions at the interfaces, highly controllable, SL epitaxy of layered organic semiconductors and heterojunctions are achievable for future devices.
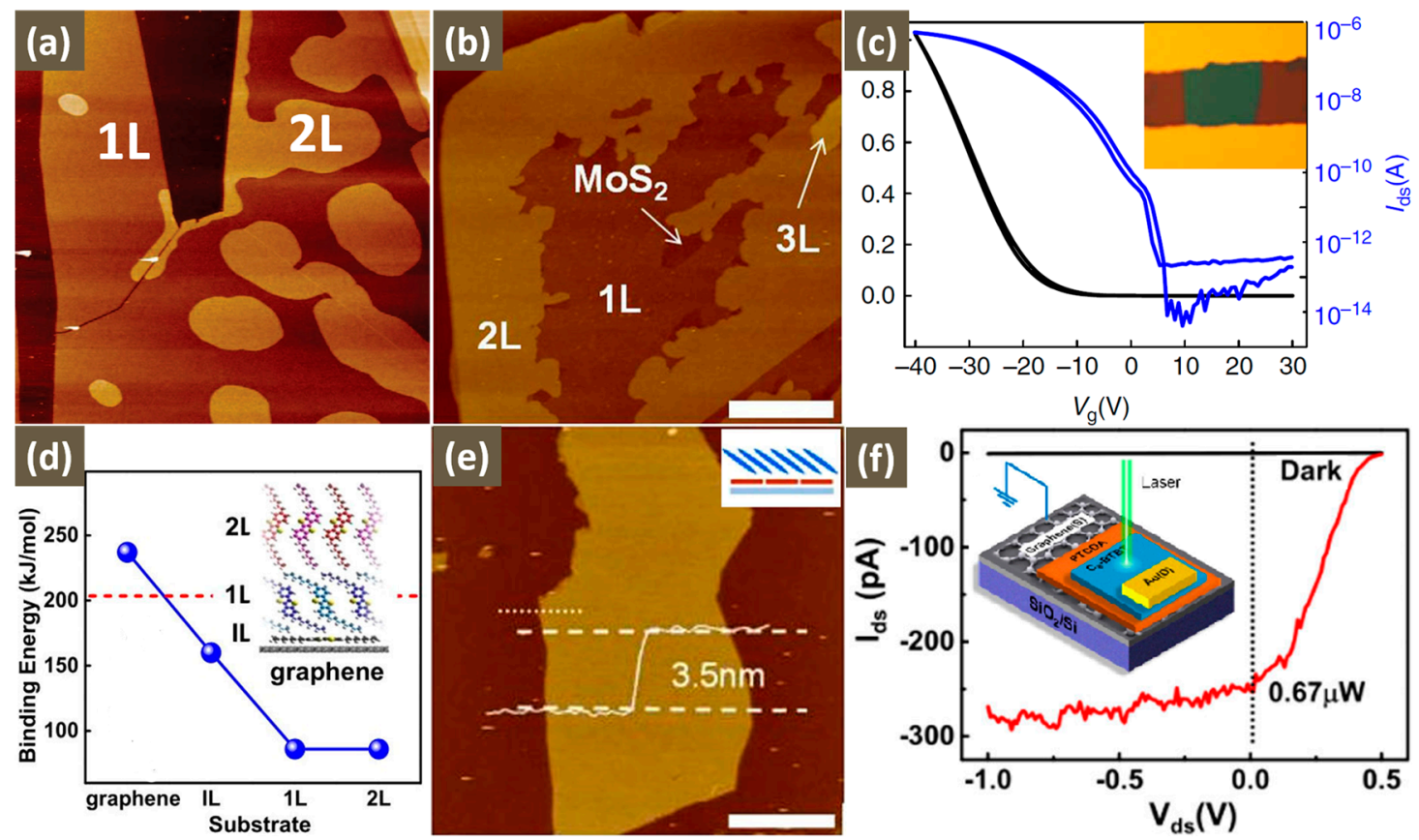

Figure 6. $\mathrm{C}_{8}$-BTBT on layered substrates. AFM image of $\mathrm{C}_{8}$-BTBT on $\mathrm{G}(\mathbf{a})$ and $\mathrm{MoS}_{2}$ (b). (c) Transfer characteristic of $1 \mathrm{~L} \mathrm{C}_{8}$-BTBT/ $h$-BN based planar OFET at room temperature. Black and blue lines are drawn in linear and log scales, respectively. Inset shows the optical microscopy image of the device. (d) Blue dots: calculated binding energies of a single $C_{8}$-BTBT molecule on G, IL/G, $1 \mathrm{~L} / \mathrm{IL} / \mathrm{G}$, and $2 \mathrm{~L} / 1 \mathrm{~L} / \mathrm{IL} / \mathrm{G}$. Red dash line: $\mathrm{C}_{8}-\mathrm{BTBT}-\mathrm{C}_{8}-\mathrm{BTBT}$ interaction. Inset shows the molecular structure of $\mathrm{C}_{8}$-BTBT and molecular packing of different $\mathrm{C}_{8}$-BTBT layers on G. (e) AFM images of SLOMBE of bilayer $\mathrm{C}_{8}$-BTBT on PTCDA. (f) Output characteristics of the $\mathrm{p}$ - $\mathrm{n}$ junction $(>15 \mathrm{~nm}$ ) under the dark conditions (black) and under the $0.67 \mu \mathrm{W}$ laser illumination. Inset shows schematic layout of the device. Panel a, c reprinted with permission from [56], copyright 2014, Nature Publishing Group. Panel b reprinted from [57], with the permission of AIP Publishing. Panel d, e, f adapted with permission from [67], copyright 2016 American Chemical Society.

\section{PTCDA on Layered Substrates}

PTCDA usually forms an in-plane herringbone structure because of intermolecular hydrogen bonding. EG is continuously over SiC step edges due to its bottom-up growth mechanism [68]. Thus, the EG-covered SiC step edges would not hamper the carpet-like PTCDA growth. As demonstrated in Figure 7a, monolayer PTCDA in a herringbone arrangement follows EG continuously over bi- and tri- SiC bilayer steps. This confirms the possibility to grow a pinhole-free PTCDA monolayer on EG. Synchrotron-based PES investigation reveals weak charge transfer and weak interactions between PTCDA and EG [68]. It is important for the functionalization of the EG surface using PTCDA derivatives to enhance the adhesion of a gate dielectric layer on EG, facilitating the growth of defect-free ultrathin dielectric layers in G-based electronic devices.

Such a self-assembled PTCDA layer can also be used as a buffer layer to protect the topological surface states (TSSs) of $\mathrm{Bi}_{2} \mathrm{Se}_{3}$, which exhibits a Dirac cone-like dispersion similar to G [69]. 
Fe deposition on bare $\mathrm{Bi}_{2} \mathrm{Se}_{3}$ results in resonance states at Fe adatoms due to Coulomb scattering between the Fe adatoms and the TSSs, and the shift of the Dirac point (DP) energy position downward by $\sim 80 \mathrm{meV}$ (doping effect) due to charge transfer from the Fe adatoms to the $\mathrm{Bi}_{2} \mathrm{Se}_{3}$ surface. On the contrary, Fe deposition on one ML PTCDA covered $\mathrm{Bi}_{2} \mathrm{Se}_{3}$ results in neither resonance states nor doping effect, as shown in Figure $7 \mathrm{~b}$, because of the charge transfer from the Fe adatom to PTCDA molecules and concentration of the Coulomb charge. Thus, organic molecules are promising as spacers in the future TI devices to prevent undesirable doping and scattering effects at the interfaces.

The highest occupied molecular orbital-lowest unoccupied molecular orbital (HOMO-LUMO) gaps of small organic molecules are dependent on the electronic screening effects from the substrate. It is measured to be $3.73,3.49$, and $3.10 \mathrm{eV}$ for PTCDA on SL WSe 2 /graphite (semiconducting), graphite (semimetallic), and $\mathrm{Au}(111)$ (metallic), respectively, as demonstrated in the scanning tunnelling spectroscopy (STS) results in Figure 7c, although the lattice parameters for these herringbone arrangements are very similar for the different substrates [70].Thus, the semiconducting 2D transition metal dichalcogenides (TMDs) layers can participate actively in hybrid organic-inorganic devices with tailored structures and properties.
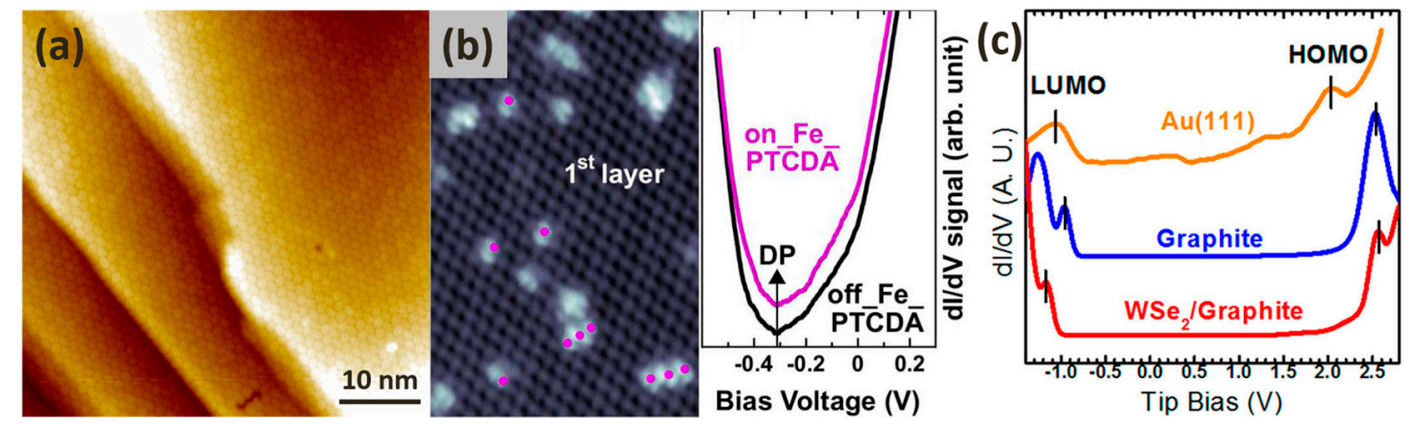

Figure 7. PTCDA on layered substrates. (a) Molecularly-resolved STM image of one monolayer PTCDA covered epitaxial G on SiC(0001). (b) STM image of $\sim 0.01 \mathrm{ML}$ Fe (protrusions) on one monolayer PTCDA covered Bi2Se3 (left) and STS curves at positions with/without Fe (purple/black, right). (c) STS curves at positions of PTCDA on Au(111), graphite, and WSe2/graphite. Panel a printed with permission from [68], copyright 2009 American Chemical Society. Panel b printed with permission from [69], copyright 2015 American Chemical Society. Panel c printed with permission from [70], copyright 2016 American Chemical Society.

\section{Conclusions}

2D layered-material templated growth is a newly developed method for fabricating high-quality organic semiconductor thin films with controllable morphologies, interface properties, molecular orientations, and electronic structures. G, $\mathrm{MoS}_{2}$, and $h$-BN show obviously different effects on the growth of pentacene, $\mathrm{CuPc}$, and $\mathrm{C} 8$-BTBT, indicating slight differences in the interfacial interactions. PTCDA can be used as protecting layer due to its inherent intermolecular $\mathrm{H}$-bonding. Large-scale high-quality 2D layered materials are required for future thinner organic (opto-) electronics like OLEDs, OPVs and OFETs.

Acknowledgments: We acknowledge the financial support from the National Natural Science Foundation (NSF) of China (Grants No. 11304398, 11334014, 51173205). Han Huang acknowledges the support from State Key Laboratory of Powder Metallurgy, Central South University and that from NSF of Hunan province (Grants No. 2016JJ1021).

Author Contributions: All authors contributed to the writing and production of this manuscript.

Conflicts of Interest: The authors declare no competing financial interests. 


\section{References}

1. Sokolov, A.N.; Tee, B.C.; Bettinger, C.J.; Tok, J.B.H.; Bao, Z. Chemical and engineering approaches to enable organic field-effect transistors for electronic skin applications. Acc. Chem. Res. 2011, 45, 361-371. [CrossRef] [PubMed]

2. Figueira-Duarte, T.M.; Müllen, K. Pyrene-based materials for organic electronics. Chem. Rev. 2011, 111, 7260-7314. [CrossRef] [PubMed]

3. Gao, Y. Surface analytical studies of interfaces in organic semiconductor devices. Mater. Sci. Eng. R 2010, 68, 39-87. [CrossRef]

4. Qian, C.; Sun, J.; Zhang, L.; Xie, H.; Huang, H.; Yang, J.; Gao, Y. Air-stable and high-performance organic field-effect transistors based on ordered, large-domain phthalocyanine copper thin film. Synth. Met. 2015, 210, 336-341. [CrossRef]

5. Huang, W.; Yang, B.; Sun, J.; Liu, B.; Yang, J.; Zou, Y.; Gao, Y. Organic field-effect transistor and its photoresponse using a benzo [1,2-b:4,5-b'] difuran-based donor-acceptor conjugated polymer. Org. Electron. 2014, 15, 1050-1055. [CrossRef]

6. Koch, N.; Vollmer, A.; Salzmann, I.; Nickel, B.; Weiss, H.; Rabe, J.P. Evidence for temperature-dependent electron band dispersion in pentacene. Phys. Rev. Lett. 2006, 96, 156803. [CrossRef] [PubMed]

7. Zhang, Y.; Qiao, J.; Gao, S.; Hu, F.; He, D.; Wu, B.; Ji, W. Probing Carrier Transport and Structure-Property Relationship of Highly Ordered Organic Semiconductors at the Two-Dimensional Limit. Phys. Rev. Lett. 2016, 116, 016602. [CrossRef] [PubMed]

8. Sadowski, J.T.; Nagao, T.; Yaginuma, S.; Fujikawa, Y.; Al-Mahboob, A.; Nakajima, K.; Tromp, R.M. Thin bismuth film as a template for pentacene growth. Appl. Phys. Lett. 2005, 86, 073109. [CrossRef]

9. Kakuta, H.; Hirahara, T.; Matsuda, I.; Nagao, T.; Hasegawa, S.; Ueno, N.; Sakamoto, K. Electronic structures of the highest occupied molecular orbital bands of a pentacene ultrathin film. Phys. Rev. Lett. 2007, 98, 247601. [CrossRef] [PubMed]

10. Huang, H.; Huang, Y.; Pflaum, J.; Wee, A.T.S.; Chen, W. Nanoscale phase separation of a binary molecular system of copper phthalocyanine and di-indenoperylene on Ag (111). Appl. Phys. Lett. 2009, 95, 263309. [CrossRef]

11. Zheng, F.; Park, B.N.; Seo, S.; Evans, P.G.; Himpsel, F.J. Orientation of pentacene molecules on $\mathrm{SiO}_{2}$ : From a monolayer to the bulk. J. Chem. Phys. 2007, 126, 154702. [CrossRef] [PubMed]

12. Ruiz, R.; Choudhary, D.; Nickel, B.; Toccoli, T.; Chang, K.C.; Mayer, A.C.; Malliaras, G.G. Pentacene thin film growth. Chem. Mater. 2004, 16, 4497-4508. [CrossRef]

13. Wang, C.; Irfan, I.; Turinske, A.J.; Gao, Y. Pinning of fullerene lowest unoccupied molecular orbital edge at the interface with standing up copper phthalocyanine. Thin Solid Films 2012, 525, 64-67. [CrossRef]

14. He, T.; Ding, H.; Peor, N.; Lu, M.; Corley, D.A.; Chen, B.; Tour, J.M. Silicon/molecule interfacial electronic modifications. J. Am. Chem. Soc. 2008, 130, 1699-1710. [CrossRef] [PubMed]

15. Lee, W.H.; Park, J.; Sim, S.H.; Lim, S.; Kim, K.S.; Hong, B.H.; Cho, K. Surface-directed molecular assembly of pentacene on monolayer graphene for high-performance organic transistors. J. Am. Chem. Soc. 2011, 133, 4447-4454. [CrossRef] [PubMed]

16. Wan, W.; Li, H.; Huang, H.; Wong, S.L.; Lv, L.; Gao, Y.; Wee, A.T.S. Incorporating isolated molybdenum (Mo) atoms into bilayer epitaxial graphene on 4H-SiC (0001). ACS Nano 2013, 8, 970-976. [CrossRef] [PubMed]

17. Huang, H.; Wong, S.L.; Wang, Y.; Sun, J.T.; Gao, X.; Wee, A.T.S. Scanning tunneling microscope and photoemission spectroscopy investigations of bismuth on epitaxial graphene on SiC (0001). J. Phys. Chem. C 2014, 118, 24995-24999. [CrossRef]

18. Wang, C.; Liu, X.; Wang, C.; Xu, X.; Li, Y.; Xie, F.; Gao, Y. Molecular orientation of copper phthalocyanine thin films on different monolayers of fullerene on $\mathrm{SiO}_{2}$ or highly oriented pyrolytic graphite. Appl. Phys. Lett. 2015, 106, 121603. [CrossRef]

19. Wan, X.; Long, G.; Huang, L.; Chen, Y. Graphene-A promising material for organic photovoltaic cells. Adv. Mater. 2011, 23, 5342-5358. [CrossRef] [PubMed]

20. Wassei, J.K.; Kaner, R.B. Graphene, a promising transparent conductor. Mater. Today 2010, 13, 52-59. [CrossRef]

21. Radisavljevic, B.; Radenovic, A.; Brivio, J.; Giacometti, V.; Kis, A. Single-layer MoS2 transistors. Nat. Nanotechnol. 2011, 6, 147-150. [CrossRef] [PubMed] 
22. Liu, H.; Neal, A.T.; Ye, P.D. Channel length scaling of MoS2 MOSFETs. ACS Nano 2012, 6, 8563-8569. [CrossRef] [PubMed]

23. Kim, S.; Konar, A.; Hwang, W.S.; Lee, J.H.; Lee, J.; Yang, J.; Jin, Y.W. High-mobility and low-power thin-film transistors based on multilayer MoS2 crystals. Nat. Commun. 2012, 3, 1011. [CrossRef] [PubMed]

24. Xiao, J.; Long, M.; Li, X.; Xu, H.; Huang, H.; Gao, Y. Theoretical prediction of electronic structure and carrier mobility in single-walled MoS2 nanotubes. Sci. Rep. 2014, 4. [CrossRef] [PubMed]

25. Jariwala, D.; Marks, T.J.; Hersam, M.C. Mixed-dimensional van der Waals heterostructures. Nat. Mater. 2016. [CrossRef] [PubMed]

26. Geim, A.K.; Grigorieva, I.V. Van der Waals heterostructures. Nature 2013, 499, 419-425. [CrossRef] [PubMed]

27. Chen, H.; Wen, X.; Zhang, J.; Wu, T.; Gong, Y.; Zhang, X.; Zhuang, W. Ultrafast formation of interlayer hot excitons in atomically thin MoS2/WS2 heterostructures. Nat. Commun. 2016, 7, 12512. [CrossRef] [PubMed]

28. Pierucci, D.; Henck, H.; Avila, J.; Balan, A.; Naylor, C.H.; Patriarche, G.; Asensio, M.C. Band alignment and minigaps in monolayer MoS2-graphene van der Waals heterostructures. Nano Lett. 2016, 16, 4054-4061. [CrossRef] [PubMed]

29. Coy Diaz, H.; Avila, J.; Chen, C.; Addou, R.; Asensio, M.C.; Batzill, M. Direct observation of interlayer hybridization and Dirac relativistic carriers in graphene/MoS2 van der Waals heterostructures. Nano Lett. 2015, 15, 1135-1140. [CrossRef] [PubMed]

30. Shih, C.-J.; Wang, Q.H.; Son, Y.; Jin, Z.; Blankschtein, D.; Strano, M.S. Tuning On-Off Current Ratio and Field-Effect Mobility in a MoS2-Graphene Heterostructure via Schottky Barrier Modulation. ACS Nano 2014, 8, 5790-5798. [CrossRef] [PubMed]

31. Sadowski, J.T.; Sazaki, G.; Nishikata, S.; Al-Mahboob, A.; Fujikawa, Y.; Nakajima, K.; Sakurai, T. Single-nucleus polycrystallization in thin film epitaxial growth. Phys. Rev. Lett. 2007, 98, 046104. [CrossRef] [PubMed]

32. Al-Mahboob, A.; Sadowski, J.T.; Nishihara, T.; Fujikawa, Y.; Xue, Q.K.; Nakajima, K.; Sakurai, T. Epitaxial structures of self-organized, standing-up pentacene thin films studied by LEEM and STM. Surf. Sci. 2007, 601, 1304-1310. [CrossRef]

33. Kelley, T.W.; Baude, P.F.; Gerlach, C.; Ender, D.E.; Muyres, D.; Haase, M.A.; Theiss, S.D. Recent progress in organic electronics: Materials, devices, and processes. Chem. Mater. 2004, 16, 4413-4422. [CrossRef]

34. Lu, J.; Yeo, P.S.E.; Zheng, Y.; Xu, H.; Gan, C.K.; Sullivan, M.B.; Loh, K.P. Step flow versus mosaic film growth in hexagonal boron nitride. J. Am. Chem. Soc. 2013, 135, 2368-2373. [CrossRef] [PubMed]

35. Götzen, J.; Käfer, D.; Wöll, C.; Witte, G. Growth and structure of pentacene films on graphite: Weak adhesion as a key for epitaxial film growth. Phys. Rev. B 2010, 81, 085440. [CrossRef]

36. Zhang, L.; Roy, S.S.; Hamers, R.J.; Arnold, M.S.; Andrew, T.L. Molecular Orientation-Dependent Interfacial Energetics and Built-in Voltage Tuned by a Template Graphene Monolayer. J. Phys. Chem. C 2014, 119, $45-54$. [CrossRef]

37. Salzmann, I.; Moser, A.; Oehzelt, M.; Breuer, T.; Feng, X.; Juang, Z.Y.; Brillante, A. Epitaxial growth of $\pi$-stacked perfluoropentacene on graphene-coated quartz. ACS Nano 2012, 6, 10874-10883. [CrossRef] [PubMed]

38. Kholmanov, I.N.; Gavioli, L.; Fanetti, M.; Casella, M.; Cepek, C.; Mattevi, C.; Sancrotti, M. Effect of substrate surface defects on the morphology of Fe film deposited on graphite. Surf. Sci. 2007, 601, 188-192. [CrossRef]

39. Mao, H.Y.; Wang, R.; Wang, Y.; Niu, T.C.; Zhong, J.Q.; Huang, M.Y.; Chen, W. Chemical vapor deposition graphene as structural template to control interfacial molecular orientation of chloroaluminium phthalocyanine. Appl. Phys. Lett. 2011, 99, 093301.

40. Jariwala, D.; Howell, S.L.; Chen, K.S.; Kang, J.; Sangwan, V.K.; Filippone, S.A.; Hersam, M.C. Hybrid, Gate-Tunable, van der Waals p-n Heterojunctions from Pentacene and MoS2. Nano Lett. 2015, 16, 497-503. [CrossRef] [PubMed]

41. Furchi, M.M.; Pospischil, A.; Libisch, F.; Burgdörfer, J.; Mueller, T. Photovoltaic effect in an electrically tunable van der Waals heterojunction. Nano Lett. 2014, 14, 4785-4791. [CrossRef] [PubMed]

42. Lee, C.H.; Lee, G.H.; Van Der Zande, A.M.; Chen, W.; Li, Y.; Han, M.; Guo, J. Atomically thin p-n junctions with van der Waals heterointerfaces. Nat. Nanotechnol. 2014, 9, 676-681. [CrossRef] [PubMed]

43. Jariwala, D.; Sangwan, V.K.; Seo, J.W.T.; Xu, W.; Smith, J.; Kim, C.H.; Hersam, M.C. Large-area, low-voltage, antiambipolar heterojunctions from solution-processed semiconductors. Nano Lett. 2014, 15, 416-421. [CrossRef] [PubMed] 
44. Xiong, F. Amplitude shift keying. In Encyclopedia of RF and Microwave Engineering; John Wiley \& Sons, Inc.: Hoboken, NJ, USA, 2005.

45. Mativetsky, J.M.; Wang, H.; Lee, S.S.; Whittaker-Brooks, L.; Loo, Y.L. Face-on stacking and enhanced out-of-plane hole mobility in graphene-templated copper phthalocyanine. Chem. Commun. 2014, 50, 5319-5321. [CrossRef] [PubMed]

46. Della Pirriera, M.; Puigdollers, J.; Voz, C.; Stella, M.; Bertomeu, J.; Alcubilla, R. Optoelectronic properties of CuPc thin films deposited at different substrate temperatures. J. Phys. D Appl. Phys. 2009, 42, 145102. [CrossRef]

47. Bao, Z.; Lovinger, A.J.; Dodabalapur, A. Organic field-effect transistors with high mobility based on copper phthalocyanine. Appl. Phys. Lett. 1996, 69, 3066-3068. [CrossRef]

48. Xiao, K.; Deng, W.; Keum, J.K.; Yoon, M.; Vlassiouk, I.V.; Clark, K.W.; Li, A.-P.; Kravchenko, I.I.; Gu, G.; Payzant, E.A.; et al. Surface-induced orientation control of CuPc molecules for the epitaxial growth of highly ordered organic crystals on graphene. J. Am. Chem. Soc. 2013, 135, 3680-3687. [CrossRef] [PubMed]

49. Jeong, J.; Park, S.; Kang, S.J.; Lee, H.; Yi, Y. Impacts of Molecular Orientation on the Hole Injection Barrier Reduction: CuPc/HAT-CN/Graphene. J. Phys. Chem. C 2016, 120, 2292-2298. [CrossRef]

50. Zhang, L.; Yang, Y.; Huang, H.; Lyu, L.; Zhang, H.; Cao, N.; Gao, Y. Thickness-dependent air-exposure-induced phase transition of $\mathrm{CuPc}$ ultrathin films to well-ordered one-dimensional nanocrystals on layered substrates. J. Phys. Chem. C 2015, 119, 4217-4223. [CrossRef]

51. Cao, N.-T.; Zhang, L.; Lü, L.; Xie, H.-P.; Huang, H.; Niu, D.-M.; Gao, Y.-L. van der Waals heterostructure about CuPc/MoS 2 (0001). Acta Phys. Sin. 2014, 63, 167903.

52. Pak, J.; Jang, J.; Cho, K.; Kim, T.Y.; Kim, J.K.; Song, Y.; Lee, T. Enhancement of photodetection characteristics of $\mathrm{MoS}_{2}$ field effect transistors using surface treatment with copper phthalocyanine. Nanoscale 2015, 7, 18780-18788. [CrossRef] [PubMed]

53. Hosoi, Y.; Deyra, D.M.; Nakajima, K.; Furukawa, Y. Micro-Raman spectroscopy on pentacene thin-film transistors. Mol. Crys. Liq. Crys. 2008, 491, 317-323. [CrossRef]

54. Chhikara, M.; Pavlica, E.; Matković, A.; Gajić, R.; Bratina, G. Effect of Water Layer at the $\mathrm{SiO}_{2} / \mathrm{Graphene}$ Interface on Pentacene Morphology. Langmuir 2014, 30, 11681-11688. [CrossRef] [PubMed]

55. Ling, X.; Fang, W.; Lee, Y.H.; Araujo, P.T.; Zhang, X.; Rodriguez-Nieva, J.F.; Dresselhaus, M.S. Raman enhancement effect on two-dimensional layered materials: Graphene, h-BN and MoS2. Nano Lett. 2014, 14, 3033-3040. [CrossRef] [PubMed]

56. He, D.; Zhang, Y.; Wu, Q.; Xu, R.; Nan, H.; Liu, J.; Shi, Y. Two-dimensional quasi-freestanding molecular crystals for high-performance organic field-effect transistors. Nat. Commun. 2014, 5, 5162. [CrossRef] [PubMed]

57. He, D.; Pan, Y.; Nan, H.; Gu, S.; Yang, Z.; Wu, B.; Ni, Z. A van der Waals pn heterojunction with organic/inorganic semiconductors. Appl. Phys. Lett. 2015, 107, 183103. [CrossRef]

58. Wang, Q.H.; Kalantar-Zadeh, K.; Kis, A.; Coleman, J.N.; Strano, M.S. Electronics and optoelectronics of two-dimensional transition metal dichalcogenides. Nat. Nanotechnol. 2012, 7, 699-712. [CrossRef] [PubMed]

59. Sachs, B.; Britnell, L.; Wehling, T.O.; Eckmann, A.; Jalil, R.; Belle, B.D.; Novoselov, K.S. Doping mechanisms in graphene-MoS2 hybrids. Appl. Phys. Lett. 2013, 103, 251607. [CrossRef]

60. Hong, J.; Hu, Z.; Probert, M.; Li, K.; Lv, D.; Yang, X.; Zhang, J. Exploring atomic defects in molybdenum disulphide monolayers. Nat. Commun. 2015, 6, 6293. [CrossRef] [PubMed]

61. Yu, Z.; Pan, Y.; Shen, Y.; Wang, Z.; Ong, Z.Y.; Xu, T.; Wang, J. Towards intrinsic charge transport in monolayer molybdenum disulfide by defect and interface engineering. Nat. Commun. 2014, 5, 5290. [CrossRef] [PubMed]

62. Smits, E.C.; Mathijssen, S.G.; Van Hal, P.A.; Setayesh, S.; Geuns, T.C.; Mutsaers, K.A.; Kemerink, M. Bottom-up organic integrated circuits. Nature 2008, 455, 956-959. [CrossRef]

63. Li, L.; Gao, P.; Wang, W.; Müllen, K.; Fuchs, H.; Chi, L. Growth of ultrathin organic semiconductor microstripes with thickness control in the monolayer precision. Angew. Chem. Int. Ed. 2013, 52, 12530-12535. [CrossRef] [PubMed]

64. Mathijssen, S.G.; Smits, E.C.; van Hal, P.A.; Wondergem, H.J.; Ponomarenko, S.A.; Moser, A.; de Leeuw, D.M. Monolayer coverage and channel length set the mobility in self-assembled monolayer field-effect transistors. Nat. Nanotechnol. 2009, 4, 674-680. [CrossRef] [PubMed] 
65. Dinelli, F.; Murgia, M.; Levy, P.; Cavallini, M.; Biscarini, F.; de Leeuw, D.M. Spatially correlated charge transport in organic thin film transistors. Phys. Rev. Lett. 2004, 92, 116802. [CrossRef] [PubMed]

66. Ruiz, R.; Papadimitratos, A.; Mayer, A.C.; Malliaras, G.G. Thickness Dependence of Mobility in Pentacene Thin-Film Transistors. Adv. Mater. 2005, 17, 1795-1798. [CrossRef]

67. Wu, B.; Zhao, Y.; Nan, H.; Yang, Z.; Zhang, Y.; Zhao, H.; Shi, Y. Precise, self-limited epitaxy of ultrathin organic semiconductors and heterojunctions tailored by van der Waals interactions. Nano Lett. 2016, 6, 3754-3759. [CrossRef] [PubMed]

68. Huang, H.; Chen, S.; Gao, X.; Chen, W.; Wee, A.T.S. Structural and electronic properties of PTCDA thin films on epitaxial graphene. ACS Nano 2009, 3, 3431-3436. [CrossRef] [PubMed]

69. Yang, H.H.; Chu, Y.H.; Lu, C.I.; Butler, C.J.; Sankar, R.; Chou, F.C.; Lin, M.T. Organic Monolayer Protected Topological Surface State. Nano Lett. 2015, 15, 6896-6900. [CrossRef] [PubMed]

70. Zheng, Y.J.; Huang, Y.L.; Chen, Y.; Zhao, W.; Eda, G.; Spataru, C.D.; Quek, S.Y. Heterointerface Screening Effects between Organic Monolayers and Monolayer Transition Metal Dichalcogenides. ACS Nano 2016, 10, 2476-2484. [CrossRef] [PubMed]

(C) 2016 by the authors; licensee MDPI, Basel, Switzerland. This article is an open access article distributed under the terms and conditions of the Creative Commons Attribution (CC-BY) license (http:/ / creativecommons.org/licenses/by/4.0/). 